\title{
The Implementation and Research of Flipped Classroom Teaching of Public Music Courses in Colleges and Universities under the Background of SPOC- Taking the Multicultural Perspective of Western Music as an Example
}

\author{
Chen Jing \\ School of Arts, Zhejiang International Studies University, Zhejiang, Hangzhou 310023
}

Keywords: SPOC; Multicultural Perspective of Western Music; flipped classroom; teaching reform

\begin{abstract}
In the view of SPOC, the public art course "Multicultural Perspective of Western Music" is combined with the blending learning led by the flipped classroom teaching. The whole process of reform and research is done through "three points and two lines", that is pre-class, in class, afterclass and online, offline, pre-school video viewing, online interaction, online testing, teamwork inclass, problem orientation, group discussion, and online feedback after class. Through online selfstudy, over-the-air thinking, offline classroom teaching mode, deep integration of "Internet + education", the subversive reconstruction of classroom teaching reform can be realized to uphold the "student-centered" teaching philosophy, optimize the teaching outcome, guide students to “engage in experience”, “active learning”, “displaying harvest”, and "applying income”, and bring new thinking direction for pattern exploration and teaching reform of public art courses.
\end{abstract}

\section{The Study of the Origin}

The public music course is an important part of the public art curriculum. It is a music course for non-music majors in colleges and universities, which aims to enhance students' aesthetic ability, cultivate their artistic sentiment and create a better mind for them. Like other public courses in colleges, the public music curriculum is an important part of China's higher education curriculum system, and it is the main approach for the implementation of aesthetic education in colleges and universities. In recent years, almost all colleges and universities across the country have begun to vigorously develop public art courses and have received extensive attention ${ }^{1}$.

The author makes a comparative study of several colleges and universities in Zhejiang province, and compares the course materials of other colleges and universities in the province ${ }^{2}$. He found that the majority of ordinary colleges and universities have achieved certain results in the construction of public art course. However, the survey also found that the current public art curriculum in colleges and universities is not new enough, mainly based on technical courses and appreciation course. The teaching model is relatively robust, the curriculum content lacks innovation, teaching methods are not advanced, and traditional teaching is still the mainstay. The lack of students' active participation can not fully arouse students' enthusiasm for learning.

\section{The SPOC Perspective of Classroom Teaching in the Design of Flipped Classroom}

Adjust and transform the teaching content of the curriculum, abandon the teaching content of "music" on "music", and rename the name "walking into music" as "a multicultural perspective of western music" with the aim of basing on history, religion, and literature, dance, ethnic culture and other multi-perspectives, "embarking into" classical music, learn to listen, feel and analyze music,

\footnotetext{
${ }^{1}$ Zhengming Cheng, Research on the Status, Problems and Countermeasures for Public Art Education in Comprehensive Universities [D].Master’s Thesis, Chongqing: Southwest University, 2008:14-22.

${ }^{2}$ Zhejiang university, Zhejiang foreign language institute, Zhejiang university city college, Hangzhou normal university, Zhejiang university of science and technology, Zhejiang university of technology, Shanghai international studies university.
} 
so as to "deep out" the cultural soil in which classical music is rooted, and to make music a culture rooted in the knowledge structure of students. Infiltrate the future life, study, and work.

Traditional music appreciation course is based on the context of the historical period, introducing composers, listening to their musical work, and memorizing musical background knowledge. However, for a limited time, it is sometimes difficult to appreciate a large number of musical works. It is difficult to understand the composer's and musical work' connotations because of limited auditory experience. Flipped classroom teaching is in the context of the Internet, forming a trinity information model of "network learning library, knowledge application and self-construction".

\section{The Characteristics of Flipped Classroom Model Based on SPOC}

SPOC derives from MOOC, whose teaching model is the rationalism result of MOOC. It combines virtual Internet with face-to-face traditional classrooms to ensure the independence, effectiveness, and enjoyment of teaching. The flipped class model based on SPOC is the deep integration of "Internet + education" which subverts traditional classroom teaching model and realizes student-centered classroom teaching. ${ }^{3}$

"Flipped Classroom" or "Inverted Classroom" teaching is a relatively new teaching model that emerged in the context of the rapid development of science and technology and the maturity of information education. Flipped classroom teaching is dubbed a subversive revolution in the classical classroom. Its greatest feature is to impart all the theoretical knowledge to students in the form of video before class. In the meeting class, students are guided to practice what they have learned, which brings the knowledge to the application level.

\section{Implementation of the Flipped-Classroom-Led Blended Teaching Model}

First of all, corresponding teaching tasks should be made according to the teaching aims. The knowledge points are treated in a fragmented manner. Each independent knowledge point is the "teaching element," and multiple parallel knowledge points form the "teaching section." The entire course "Multicultural Perspective of Western Music" is divided into five major units according to the knowledge structure. There are ten modules which are closely connected and logically linked to form a complete curriculum system.

Second, curriculum teaching resources should be established. Independent micro-video should be shot according to each knowledge point "teaching element". Based on teaching video, teaching PPT, pre-class homework, brainstorming questions, after-class test, expand audiovisual ${ }^{4}$ materials and other forms of teaching resources should be produced for students to carry out online learning.

In flipped classroom teaching, the author made a generative dynamic classroom as an effective teaching method for internalizing knowledge. In the classroom teaching, adhering to the teaching concept of "experience participation, concept exploration, meaning construction, and display application", we strive to find the generating points of classroom teaching and position the center of preparation for lessons in a multifaceted process, multiple conclusions, multiple methods, and analysis of knowledge. The occurrence and formation of the process, mining, expanding the content of the teaching middle school students are prone to questions and interest, focus on student preferences, emphasis on the application of music and cultural knowledge in life and learning, consciously broaden their horizons, expand the horizon of learning accumulation before class, collide in-class, update after class, design classroom activities that match the teaching content, provide students with the most suitable practice place, and encourage students to boldly use their own study habits and methods to engage in dialogue with the living world. , The use of the course

\footnotetext{
${ }^{3} \mathrm{Yi}$ Wang. The problem of art education efficiency in colleges and its improvement path research -- an empirical analysis of non-professional music education. [D]. PhD thesis, Nanjing: Nanjing Agricultural University, 2014: 90-110.
}

${ }^{4}$ Ying Liu. Curriculum reform based on "flipped classroom". [J]. Higher Education in China, 2008(18):36-38. 
network platform to communicate within and outside the classroom, online and offline, the integration of teaching content restructuring, through the teacher's pre-class construction and classroom generation, and continue to stimulate students to internalize the curriculum knowledge and application.

After the end of the offline interview course, before entering the original unit, students need to go back to the online platform to provide feedback on what they have learned. First, each group summarizes and reflects on the content discussed and displayed in the classroom, and shares it with other groups. Second, it reviews and analyzes the performance of other groups and the contents of the presentation; Finally, students complete unit tests separately to assess learning.

The following figure presents the implementation steps of flipped classroom teaching design:

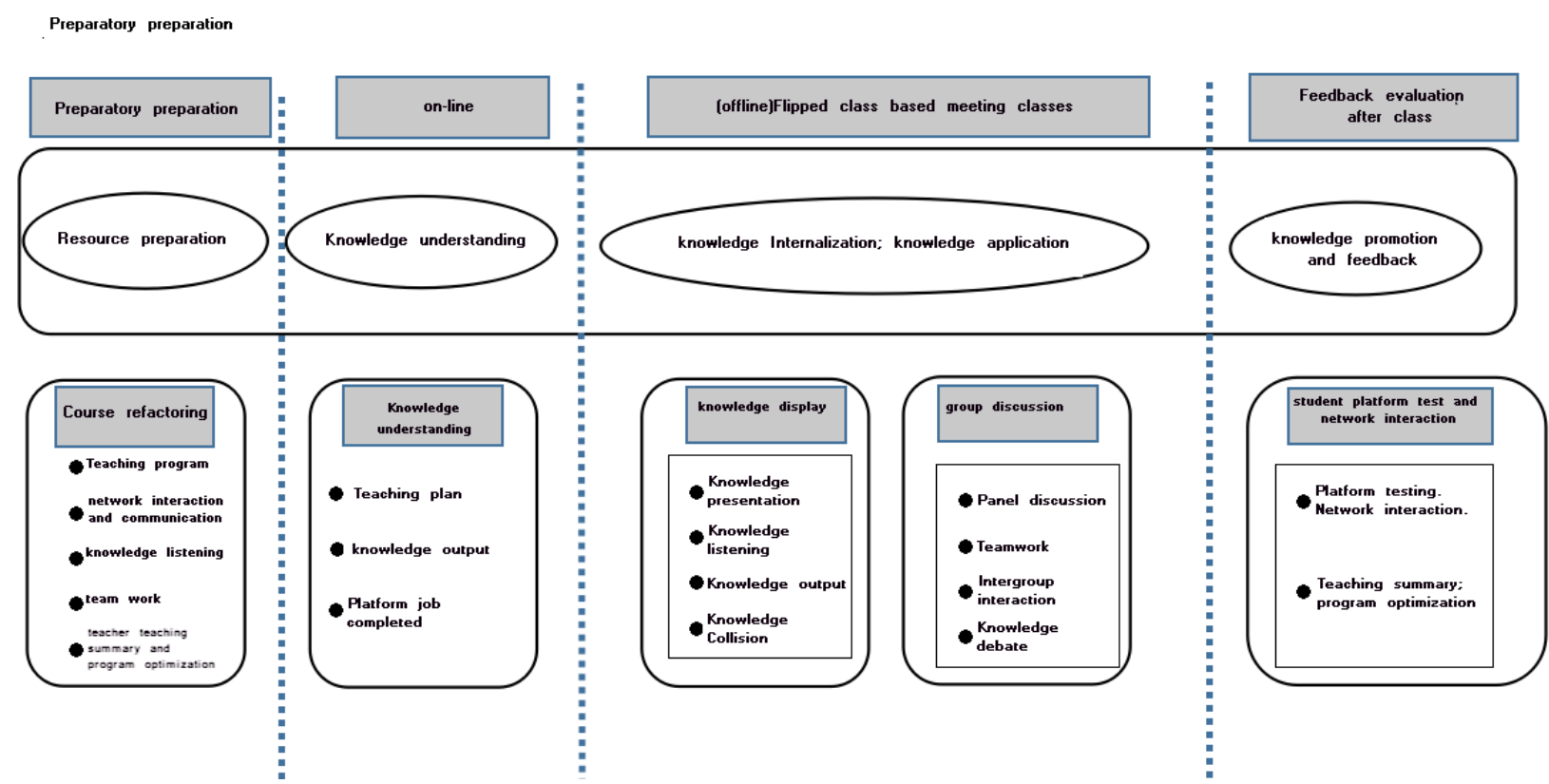

Figure 1: "Multicultural Perspective of Western Music" Course Teaching Design

\section{The Strategy of Flipped-Classroom-Led Blended Teaching Model}

Under the constructivist theory of the "three-fold musical intelligence" capacity building model ${ }^{5}$, the way people establish connections with the world is information processing, information construction, and wisdom generation. Through the previous input of music theory knowledge and music information (online video viewing), integration and construction (learning under the wire to meet classes), it finally comes out musical skills and musical wisdom that students need for individual development. (see figure 2)

${ }^{5}$ Ziqiang Xin. Knowledge construction research: from doctrine to demonstration. [M]. Beijing: Educational Science Press, 2006:71. 


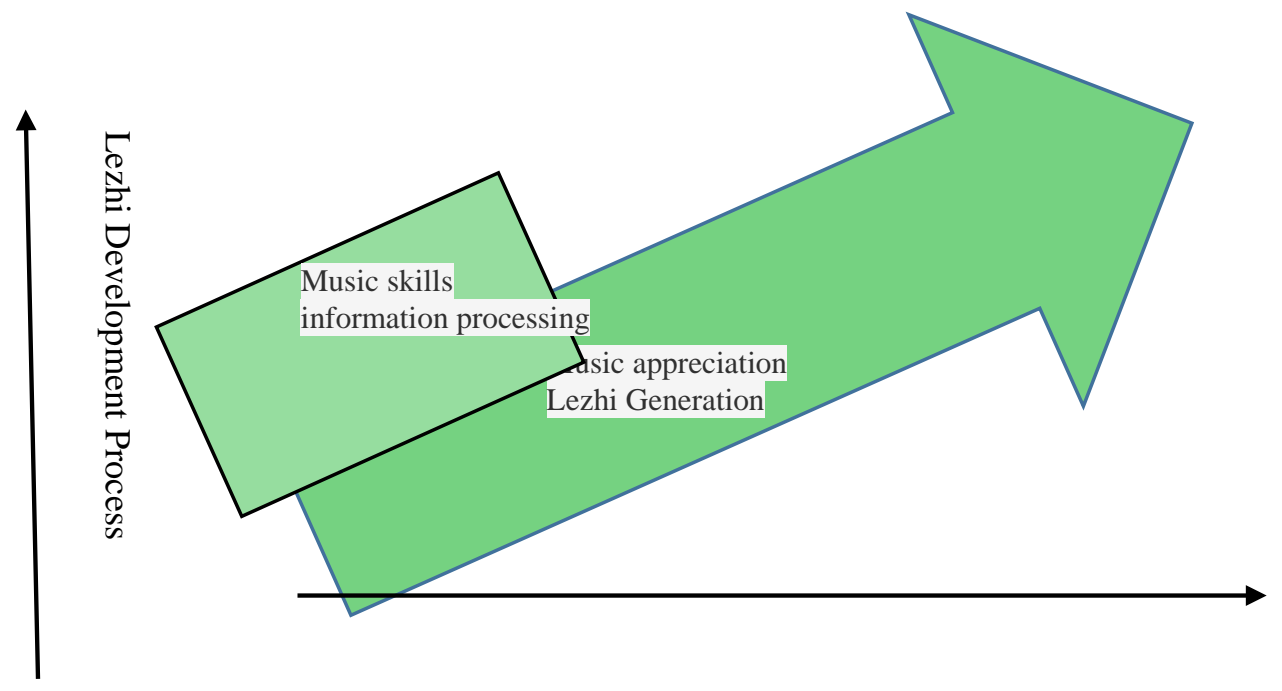

Figure 2: "three fold musical intelligence type"capacity building model

The MEI music teaching model takes music as the core, experience as a method, interact as a form, and adopts the combination of "scientific theory, listening, feeling, analysis, and creation", the design of inquiry-oriented teaching process. Discovering learning potential, stimulating interest in music, cultivating creative thinking, and forming a spiral teaching method with Mini-quiz Learning as the lead line, Team-based Learning as the main line, and Project-based learning as the subordinate line. Learning around each link online and offline, taking project-based team learning as the main teaching method, and equipped with corresponding quizzes to instantly check students' situation.

\section{Conclusion}

As a public art course, "Multicultural Perspective of Western Music" is a liberal arts and social sciences general course with a certain degree of professionalism. It is an important exploration of the deep integration of educational technology and college music general knowledge course. Students need precise input skills (listening, appreciation), also a lot of output skills (expression, thinking, discussion) during the learning process. Before the lesson, have a perceptual thinking in the video teaching of the knowledge points and music listening, while in the class, think, discuss and think about the feelings of knowledge points and music listening. Prompting the students to move from the passively input learning mode to the initiative. Input-output combined with researchbased teaching, stimulates students' enthusiasm for learning and desire for exploration, ultimately helping students to gain theoretical knowledge and application skills more effectively.

\section{References}

[1] Zhengming Cheng, Research on the Status, Problems and Countermeasures for Public Art Education in Comprehensive Universities [D]. Master's Thesis, Chongqing: Southwest University, 2008:14-22

[2] Ying Liu. Curriculum reform based on "flipped classroom". [J]. Higher Education in China, 2008(18):36-38.

[3] Ziqiang Xin. Knowledge construction research: from doctrine to demonstration. [M]. Beijing: Educational Science Press, 2006:71. 